Send your letters to the Editor,

British Dental Journal,

64 Wimpole Street

London

W1G 8YS

Email bdj@bda.org

Priority will be given to letters less than 500 words long.

Authors must sign the letter, which

may be edited for reasons of space.

\section{FLUORIDATION DEBATE}

Sir, in 1956 when taking my LDS finals examination I correctly assumed there would be a question about fluoridation of the public water supply!

In 1969, while attending the DDPH course at Leeds Dental School, fluoridation was much in the minds of Professor Jackson and John Murray, which reflected the public debate about the merits of further fluoridation at that time.

In 1975/76, as Area Dental Officer for Sefton AHA, being convinced that fluoridation was effective in lowering the incidence of dental caries, I robustly promoted the fluoridation of the water supply in Merseyside both to the Area Health Authority and in public debate. Nothing happened and now here we are a further 30 years on and Southampton PCT, among others, is discussing whether they should fluoridate the local water supply. But now I am less confident of the cost benefit of the proposal.

A cursory review of the literature (and at age $78 \mathrm{I}$ am not keen on doing more than a superficial trawl of the research) suggests that the marginal benefit gained in caries prevention on top of that already gained by fluoride in toothpaste, in drops and by topical application, is far less clear cut than was the case when the incidence of caries was so much higher as at the time when the measure was first promoted.

It is of consequence to note that reparative treatment today is much less destructive of tooth tissue and also that, to an extent, modern dental practice with its concentration on preventative measures probably has had some impact on the DMF rates.

The limited number of surveys I have perused tend not to show whole lifetimes' experiences of dental caries; indeed sometimes to my surprise they concentrate almost exclusively on the deciduous dentition.

Be that as it may, a key factor that contributes to my unease about supporting the proposal is that the Public Health Authorities seem somewhat less willing now to assert that there are definitely no long term adverse effects (save for dental fluorosis) on the recipients' general wellbeing than they were when I was actively promoting the measure so long ago!

In conclusion at this time of stringent financial restraints and with much public antipathy, I just wonder now if the marginal benefit of the fluoridation of the public water supply is worth pursuing?

J. Doughty, Ringwood

DOI: 10.1038/sj.bdj.2009.122

\section{LATEX STATUS}

Sir, I write further to the letter by R. Evans of Kidlington (BDJ 2008; 205: 523) addressing a patient's concerns of latex 'allergy' to a toothbrush, which may very rarely be elicited by contact with the handle of the toothbrush or the on/off button of the electric toothbrush during use, assuming these are 'always' latex derivatives. Moreover, with the advent of advancing trends and products in oral care, there is a lot of competition amongst the leading manufacturers to ensure products are latex free.

In our experience, true latex hypersensitivity in an individual resulting from toothbrush use or contact requiring hospital treatment has not been reported before. We would however, strongly advise individuals interested in purchasing dental products to obtain their own verification of the latex status of any product directly from the product supplier or manufacturer.

R. Paul

Portsmouth Hospitals NHS Trust DOI: 10.1038/sj.bdj.2009.123

\section{CHARCOT-MARIE-TOOTH}

Sir, both we as doctors and our patients suffer due to easily accessible online websites for diagnosing illnesses. One patient came to my practice very distressed. He entered my room with an open laptop in his hand accompanied by his concerned brother. This patient had been suffering from a headache radiating from his teeth to almost the tip of his toes, he said. He also complained of a weak jaw joint on the same side. It was of course a TMPDS case, but the interesting thing was that the patient said he went to several doctors for the condition and had the bridges, crowns and even teeth on both the arches removed and finally searched on the Internet and diagnosed his condition as Charcot-Marie-Tooth disease. The name sounded a bit familiar to me, but I was convinced that it was nothing related to the teeth. I did not check it on the Internet in front of the patient, but just reassured him and his brother that there was nothing wrong with his teeth and also advised a psychiatric consultation to relieve his stress.

When I checked out the disease on the Internet myself I realised that I should have clarified in front of the patient that this disease has no association with the teeth and its name is derived from the names of the three physicians who first identified it (in 1886): Jean Martin Charcot, Pierre Marie, and Howard Henry Tooth.

N. Harris

Dubai

DOI: 10.1038/sj.bdj.2009.124 


\section{QUESTIONING PRACTICALITY}

Sir, I was drawn to the current thread of correspondence $^{1,2}$ relating to dry socket, as it is an area which I have taken considerable interest in over recent years.

Having established a new in-hours emergency dental service in Oldham in 2006 we found our appointment books were filling quickly, with pressure falling on appointment slots to the extent that the incidence of post-operative complications was impacting on service capacity and efficiency.

With roughly half the patients accessing our service receiving an extraction we had no problems conducting an audit of hundreds of cases, finding our service incidence rate of dry socket to be about $5 \%$, with a noticeable variation between operators that proved hard to explain given the consistency of approach to case selection and care.

We resisted the temptation to draw too much inference in comparison of our results with the wide variation in reported rates of dry socket given our understanding of the complex array of variables in the presentation, diagnosis and recording of complications. Our concern from the outset was to reduce the incidence as much as we could for the benefit of our patients and those we were at risk of turning away.

In our consideration of measures we could implement we made reference to the national clinical guidelines on the prevention of dry socket. ${ }^{3}$ We were looking for simple measures over which we would have control, that were cheap, practical and easy to administer, and that were evidence based.

As a result we decided to implement a simple regimen of one minute, pre-operative chlorhexidine mouthwash rinses in an effort to reduce plaque levels pre-operatively, which on further audit revealed an immediate reduction in our dry socket incidence of 50\%. This represented a considerable saving in patient suffering and inconvenience, and freed up our appointment slots for more urgent care.

Whilst I appreciate that the national guidance was evidence based I am caused to question the practicality of two of the suggested preventive measures: that patients who smoke should be 'enjoined to cease the habit pre-operatively and for at least two weeks post-operatively'; and that 'wherever possible, for female patients using the oral contraceptive extractions should be performed during days 23 through 28 [sic] of the tablet cycle'.

I would be interested to hear if anyone has managed to implement either of these measures with any success!

G. Scott

Blackmoorfoot

1. Speechley J A. Dry socket secrets. Br Dent J 2008; 205: 168

2. Williams P R. A single dose. Br Dent J 2008: 205: 525.

3. Faculty of Dental Surgery, Royal College of Surgeons of England. National Clinical Guidelines. Management and prevention of dry socket. Para 2. 1997.

DOI: $10.1038 /$ sj.bdj.2009.125

\section{BEYOND THE PALE}

Sir, I must register my strong disapproval of a progressive commercial bias in what I have always assumed to be an unbiased professionally refereed science based journal. It is unacceptable to name any company associated with a clinical evaluation of all-ceramic bridges (BDJ 2008; 205: 477-482) that no doubt also pays the bills for what is purely and solely an advertising platform. I would not wish to go any further by challenging the content on scientific grounds.

I have spent a considerable amount of time over the years attempting to introduce proper standards in dentistry, so far with very little success. This article even mentions the use of a 'calibrated examiner', whatever that may mean - is it a person or perhaps a software tool? This whole area of employing CADCAM technology needs to be addressed in a fundamental manner in which the relevant standards, already in place and well known in the engineering industry, should be embraced and adapted accordingly. The frequent mention of the commercial enterprise associated with this refereed scientific article is frankly beyond the pale and devalues the credibility of the $B D J$. The proper place to publish these results is in a monograph funded by the company concerned or alternatively in the advertising section of the $B D J$ having paid the appropriate fees.

N. J. Knott
Chippenham
The authors R. J. Crisp and F. J. T. Burke respond: We thank Dr Knott for his interest in our paper which followed accepted guidelines for the use of trade names in published research papers ie full company details when the product is first mentioned and if that company also happens to be the funder of the research this is clearly stated in an acknowledgement. We are sure that if the company (Renishaw plc. New Mills, Woottonunder-edge, Glos, UK) to which he is an advisor funded a three-year clinical evaluation (now extended to five-years) that company would also want their contribution acknowledged.

Surely Dr Knott is aware that the funding of research by ethical manufacturers is not unusual, and indeed could be considered to be essential, so that their products may be tested, either clinically or in the laboratory, by independent researchers and that the research is then published in the public domain. In this respect, three of the 12 research papers in one recent issue of another peer-reviewed scientific dental journal acknowledge funding from manufacturers. ${ }^{1-3}$

We are surprised that your correspondent is not aware of the term 'calibrated examiner'. The context of this term 'examiner' is clearly stated in the paragraph detailing the annual review of the restorations but if your correspondent is aware of a software tool that will examine restorations we would be most interested as we will all soon be redundant!

Lastly, we note that $\mathrm{Dr}$ Knott wrote a remarkably similar letter ${ }^{4}$ in 2007 in response to a paper on the 3M ESPE Lava system $^{5}$ and being aware of his interest in the science of measurement (metrology) we wish him well in his endeavours.

1. Ohlmann B, Rammelsberg P, Schmitter M, Schwartz $S$, Gabbert O. All-ceramic inlay-retained fixed partial dentures: preliminary results from a clinical study. J Dent 2008;36:692-696.

2. Chen L-J, Meng Q-F, Chen Y-M, Smales R J, Yip K $H$-K. Effect of fluoride intophoresis on the microtensile bond strength between dentin and two adhesive systems. J Dent 2008; 36: 697-702.

3. Farrell S, Barker M L, McMillan D A, Gerlach R W. Placebo-controlled trial evaluating safety with $12-$ months continuous use of $6 \%$ hydrogen peroxide whitening strips. J Dent 2008; 36: 726-730.

4. Knott N J. Source of concern. Br Dent J 2007; 203: 440-441.

5. Barnfather KPD, Brunton P. Restoration of the upper dental arch using LavaTM all-ceramic crown and bridgework. Br Dent J 2007: 202: 731-735.

DOI: $10.1038 /$ sj.bdj.2009.126 


\section{NO MORE LEAKS}

Sir, I would like to inform your readers of a simple solution to the irksome problem of leaking local anaesthetic cartridges used in dental syringes.

Leaking cartridges do not only delay procedures and annoy the patient - as the solution runs into their mouth or down their chin - but does not allow for an accurate record of the amount of local anaesthetic administered.

If the cartridge is found to be leaking, replace the cartridge in the syringe but ensuring the end of the needle penetrates the centre of the bung of the cartridge, rather than towards the periphery.

It is this peripheral oblique placement that prevents a satisfactory seal from being achieved and allows leakage to occur.

\section{Robertson}

London

DOI: 10.1038/sj.bdj.2009.127

\section{RECORD UNBROKEN}

Sir, I was interested in the light-hearted letter from W. R. Field (BDJ 2008; 205: 468-469) when he described inlays that he had produced in a patient 55 years ago whilst a student, which were still as good as when they were inserted, and asked if this record could be beaten. We were students together at Birmingham Dental School in the mid-1950s.

In my case I don't think his record can be beaten. The ones he did for me then have all fallen out.

R. A. Standing Kingsbridge

DOI: 10.1038/sj.bdj.2009.128

\section{CREDIT DUE}

Sir, I was interested in Peter Swiss's article in the $B D J$ celebrating the 21st anniversary of Denplan (BDJ 2008; 205: 475-476) but I thought I could provide a bit of historical background. In 1972 Tom Farrell, Keith Marshall, the late Tony Love and I put forward a novel dental insurance scheme which we called the 'Private Dental Scheme'. At that time most of us could see that the NHS was developing into a never-ending treadmill, and the harder you worked, the less you would be paid. Seeing the disadvantages of both the 'piece work' and 'capitation' schemes I had designed a novel system that I thought would work better, similar to an annual 'service' fee you pay your plumber. It was an entirely unknown concept at the time.

I spent about $£ 5,000$, a lot of money in those days, to get past the then Board of Trade who wanted to label it an insurance scheme, asking us to put down a deposit of $£ 100,000$ ! Subsequently we took legal advice and had the literature printed (Fig. 1).

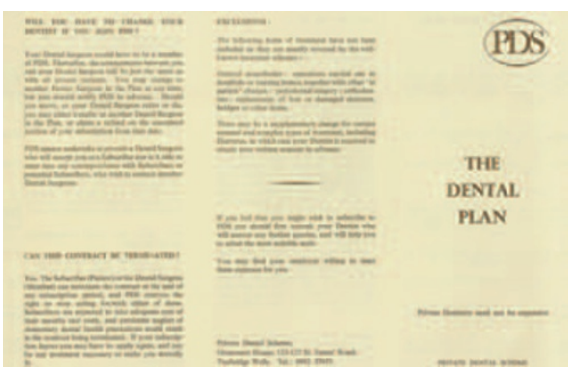

Fig. 1 Private Dental Scheme literature from 1972

We held a meeting at the postgraduate centre in Tunbridge Wells in late 1972. A large number of dentists attended but most of them were earning a lot of money in the NHS and did not wish to rock the boat. I do remember the comments of Peter Swiss who said 'You are just changing one authority for another'. Anyway only a handful seemed interested and we filed it. Soon after that Tom became chairman at the Dental Estimates Board and Keith moved to King's Hospital.

Thirteen years later in 1985, the profession had become much less satisfied with Health Service dentistry and I wrote to the BDA re-emphasising the plan's advantages. Peter Swiss replied saying he would put it to the executive and let me know. I sent him all the details of the plan but heard no more.

In his article Peter says 'It was in the mid 1980s, whilst working with me at the Medical Defence Union, that Stephen Nora and Marilyn Orcharton met and devised the idea of a private capitation scheme'. As you would know the initial Denplan was almost identical to our Private Dental Scheme and I thought that some of the credit should go to those who first conceived the idea.

\section{J. Mew}

By email

DOI: 110.1038/sj.bdj.2009.129 